\title{
Gender Differences in Innovation Design
}

\author{
A Thematic Conversation Analysis
}

\author{
Alice Ashcroft \\ School of Computing and Communications, Lancaster University, Lancaster, UK, \\ alice.ashcroft@lancaster.ac.uk
}

\begin{abstract}
This study investigates aspects of the role gender plays in participatory design innovation workshops; reflecting on both the process and the output. Often when gender and design are discussed, the problems raised concern a lack of women as designers or developers [1], but there is little on ensuring full gender representation when it comes to users. In this study, a design workshop was run where participants were asked initially to identify or generate problems and possible digital solutions concerning their academic studies, and then to design their top self-selected solution. The workshop was recorded and transcribed, and a thematic conversation analysis was carried out which found gender to influence problem raising, language used and group practices. The paper concludes both that gender apparently plays a strong role in group dynamics with regards to design innovation; and that thematic conversation analysis provides an appropriate and insightful approach to understanding these issues.
\end{abstract}

\section{CCS CONCEPTS}

- User Characteristics • Interaction Design • Human Computer Interaction (HCI)

\section{KEYWORDS}

Gender, Innovation, Design Workshop, Participatory Design, Conversation Analysis, Thematic Analysis, Thematic Conversation Analysis

\section{Introduction}

Often when gender and design are discussed, the problems raised concern a lack of women as designers or developers [1], but there is little on ensuring full gender representation when it comes to users. This issue is critical to consider; as it is not just women who make up half the design or development team, but the users themselves. The possibility that the female contribution to design and innovation should be regarded as important if not fundamental. Women are, and should be given equal opportunity to be, designers and users, and contributions should be encouraged and supported. As such, this paper aims to outline and consider how gender roles play a part in innovation and design with regard to users, as well as designers, by examining any gender differences in design innovation workshops. There are other studies considering Conversation Analysis (CA) and gender e.g. Stokoe and Weatheral [2], but a much more limited number on how this ties in to innovation and ideation. Consequently, this study focuses on the analysis of gender in the creative process and decision making in small group or workshop settings employing forms of participatory design.

Participatory Design (PD) as an innovation workshop, is the act of involving stakeholders in the design process to ensure that all requirements are thought out and well designed and implemented. As a methodology, PD has been used to format workshops [3], which is how it was used in this study. Hansen et al. [3] state, their claim "is not that PD is superior to other approaches" but that an increased interest in HCI should be matched by an increased interest in PD. However, their paper holds a variety of reasons as to why PD is the only way to achieve a design which both users and designers would be able to work with, and other literature supports this. Hansen et al. also state that PD is "not merely a collection of participatory methods or about having an ethical standpoint in design, but an approach to generate effects related to democracy, empowerment, and quality of process and product" [3] which supports any interest in diversity and design 
through PD. The aim of this paper is to uncover to what extent gender is a factor within conversation with PD being used as a framework, as well as the effect that this has on its suitability in organisations.

Innovation has been defined as the creation and adoption of an idea, a product, a technology, or a program that is new to the group using it [4]. In line with this, Fagen [5] describes innovation as being able to be focused on one of three areas: person, process or product. Ideation in the context of this study, will focus upon innovation in products. Generating ideas, which could be linked to people or process, with the understanding that the act of creating the idea itself will often, but not exclusively, lead to a product.

Using an ideation method, such as an 'inspiration card workshop' can lead to ideas which can then be used in a Prototyping activity [3]. If this uses both the users and the designers in a collaborative model, this can be referred to as 'Cooperative Prototyping' [3]. Steen [6] states that through the lens of virtue ethics that it is the traits of cooperation, creativity, empowerment and reflexivity that allow PD to flourish as a means of design, but extends this not just to the users and designers, but also to researchers and other stakeholders.

Since design is often staged through workshops supported by collaboration and cooperation, it is important to consider the effect that gender has on research method. In a paper published in 1997, Balka [7] extended the "analysis of gender as a factor in participatory design initiatives", and achieved this by focusing on "the challenges of implementing PD in the context of non-profit feminist and women's organisations" [7]. The main challenge encountered in using PD as a framework for design in these organisations was how this process fitted into the organisational structure at large [7]. This is particularly relevant to this research within a University setting, as if only a subsection of diverse groups are surveyed and given opportunity to be involved in the process of design, then the products and services made available to students may not be suitable for all. Moreover, overall Blaka [7] supports the argument that PD is "likely to fail unless the gendered nature of expertise is recognised".

Alongside an intellectual commitment to a PD approach, it is also important to consider how research findings are impacted by the methodology and data collection methods, and how individual participants interact with one another. This ties back into reflexivity and the work of Hester and Francis [8] which is discussed more in depth below. In this study design was carried out in a group setting, and therefore it is important to consider how gender effects this conversation in groups. The 'gendered reality' of research must be carefully considered [9], specifically when it comes to language and conversation. This 'gendered reality' refers to the fact that in participants identifying with gender and having been raised with certain gender roles, this is the reality in which research is being carried out, and therefore this cannot be overlooked. Conversation analysis is one way of analysing any gender differences [9].

Conversation analysis (CA) is "an approach to the study of social interaction that emerged through the collaborative research of Harvey Sacks, Emanuel Schegloff, Gail Jefferson, and their students in the 1960s and early 1970s" [10]. Feminist conversation analysis is carrying out CA critically reflecting on any research previously carried out using CA, or how the method is used. Kitzinger [11] claims that "it is clearly not the case that CA is (or can readily be made) compatible with all variants of feminist research", suggesting that only certain elements of the method should be adopted to carry out truly feminist research. Feminist methodologies are built on the argument that the traditional "'rules' of research have embedded within them an unconscious patriarchal bias" [12]. One of the main concerns around this is that this goes undiscussed and any prior knowledge, assumed as general knowledge, may have come from a place of male bias. To overcome this, any research carried out must not rely on any previous research when results are analysed. Davis [13] argues that diversity is "not only essential as a goal of intersectional feminism, but also as a means of continuing success for digital movements", all of which are aims of this research so must be considered when drawing on previous research.

One of the propositions made in this paper is to present a Thematic Conversation Analysis (TCA) method. This will be a combination of thematic analysis and CA, allowing conversations and discussions to be 
analysed and the main topics to be examined in further detail. Building on fundamental principles from CA, such as turn-taking [14] and language used [2], this process will also enable themes outside of the conversation structure to be examined such as; the types of ideas being brought forward, the meaning of the language being used. However, this will also allow classic CA examples of group practices to be examined such as leading and turn taking.

\section{Methodology}

The methodology of PD, has a set structure given that it is a research methodology [15]. This three-stage method includes; "initial exploration of work", "discovery process" and "prototyping" [15]. In this study, the method of "initial exploration" was in the form of an innovation workshop. Innovation Workshops are a style of focus group, where participants are encouraged to adopt an innovative and creative thinking style. In this particular case this included; independent ideation around problem areas, followed by collaborative grouping. The "discovery process" was done through independent ideation of solutions around those problem areas, with the "prototyping" being carried out by the group at large. Ideation, in this instance, refers to the process of noting ideas around a topic on a sticky note. Many innovation workshops are based around this method of ideation; the differences lie in the topics of ideation and how these are derived [16].

Building upon the research and literature surveys of Stokoe and Weatheral [2] and Sidnell [10], CA as a means of evaluation is well rehearsed. "CA provides the tools to explore in fine detail how issues around gender are occasioned in talk" [17]. However, this practice focuses on how things are said, and the interactions between participants. The aim of this study was to find the role gender played in a group setting with regards to innovation and PD. Therefore, as well as understanding how interactions took place, there also needed to be a focus on what was being said. In looking at the way participants interact with one another, it is important to understand the more subtle differences in language. Stokoe and Smithson [17] state that CA is a "fruitful way of exploring links between gender and discourse", because "rather than imposing the analyst's assumptions on to the data in which gender may be relevant, CA focuses on what participants themselves focus to talk on".

Thematic analysis is used to extract themes from a text, or "thematic analyses move beyond counting explicit words or phrases and focus on identifying and describing both implicit and explicit ideas within the data, that is, themes" [18]. Applied thematic analysis ties together "grounded theory, positivism, interpretivism, and phenomenology" into "one methodological framework" [18]. However, the suggestion that thematic analysis ties all these methodologies together is a bold claim. For example, positivism and interpretivism are quite different on what counts as knowledge. Understanding how thematic analysis ties into methodologies at large was crucial to be able to carry this research out effectively. However, in carrying out a thematic analysis, it was important not to lose any gender difference that would have presented themselves through conversation analysis.

The solution presented in this research is to combine the two approaches of thematic analysis and conversation analysis to allow the thematic analysis of the conversation whilst paying attention to the understood patterns of CA. This combination of methodologies will be referred to as Thematic Conversation Analysis (TCA). The process of TCA involves taking a transcript of a conversation, in this study this was a PD session with a group of university students, and working through to uncover themes, either in how concepts are discussed (this comes from CA) or what they are discussing (this comes from thematic analysis). It is understood that thematic analysis involves "more involvement and interpretation from the researcher" [18]. Such an approach clearly raises issues of reflexivity, and validity, and therefore generalisation of any results to a wider sample of population. This is discussed in further detail below (4.1.1). 


\subsection{The Context of the Study}

The study took place with seven University students, who took part in a workshop with the department who provide IT services to the University. Prior to the workshop, the students completed a basic diversity survey. The benefits of a survey include the ability to measure quantitatively and place a numerical value on the differences between participants. As well as this, a survey maybe a comfortable way of divulging information for participants, as falling into a bracket could be a much less personal way divulging who they are. The survey used in this study categorised participants based on the attributes: gender, age, ethnicity, religion, disability and sexuality. However, in this analysis, we will be focusing solely on self-selected gender identity as the scope for diversity. The participants have been numerically ordered for anonymity and given a prefix or ' $\mathrm{F}$ ' for female and ' $\mathrm{M}$ ' for male. Therefore, the participants are: F1, M2, F7, F8, M9, F10, and F12. The participants selected their own seats on arrival.

Firstly, in isolation, participants were asked to write down any problems they, or friends and peers, faced around their academic studies. In total 37 problems were raised. The participants were then asked to pair up and to explain their problems to each other, in preparation to present the problems their partners had raised to the rest of the group.

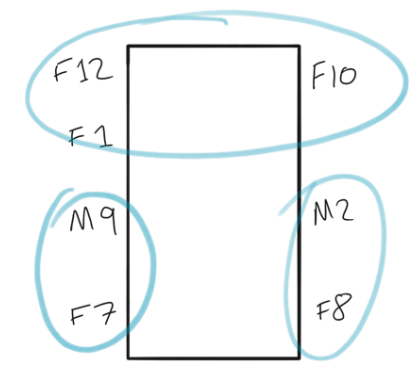

Figure 1: How participants chose to group themselves to share problems with one another for the 'Academic Outcome' workshop.

Figure 1 (above) shows how the participants chose to 'pair up' to discuss their problems with one another. This made two mixed gender parings, and one group with three women. After discussion between the smaller groups, they were then asked to present one another's problems and pain points to the rest of the group. M9 went first, presenting F7's notes to the team. M2 presented the problems of F8 first.. The group made up of F1, F12 and F10 had mixed all the sticky notes together and presented these as a group, each taking it turns to present the next sticky note that was picked up.

They were then asked as a team of seven, to categorise their problems into 'Problem Categories'. F1 began writing out Problem Category headings, with M9 suggesting these titles. It was F1 who once they had some categories decided that suggested, "let's put these ideas by the categories and see if there's any left". They then seemingly worked in their original parings to place the sticky notes under each of the headings.

After categorising the 37 problems, the participants were then asked to individually ideate around the problems that had been raised. On completion, they were then asked to present their ideas to the team. They presented these clockwise around the table, starting with F8, after being asked by M2 to start.

After each of the ideas had been read out, they were asked to pick the top three ideas. They did this by choosing the category that was important to the majority of the team. This discussion was led by M2. After this, they were asked to fill in a Business Canvas Model [19] for each of the three ideas. They broke up into smaller groups again, unprompted, this time in the following format. 


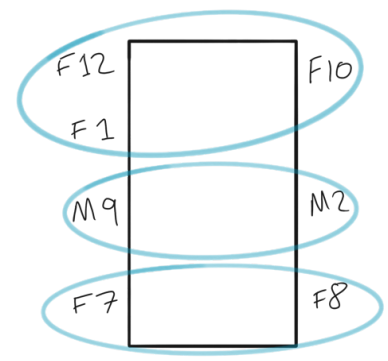

Figure 2: Participant's self-selected grouping for the completion of a business canvas model for their three top ideas.

The Business Model Canvas [19] involves the expansion and further exploration of an idea (see Figure 3). This group ran as part of an innovation workshop at the University, where these completed canvases are used to inform business cases. Therefore, this was done to encourage the participants to think more in depth about their idea including what problems they were trying to solve, how the solution would work, as well as what makes their solution unique. The participants were then asked to selected their top idea and complete designs for this. The top idea that was chosen was an improved timetable for students, with additional features. Currently the timetable system for the University only displays scheduled classes, exams and deadlines.

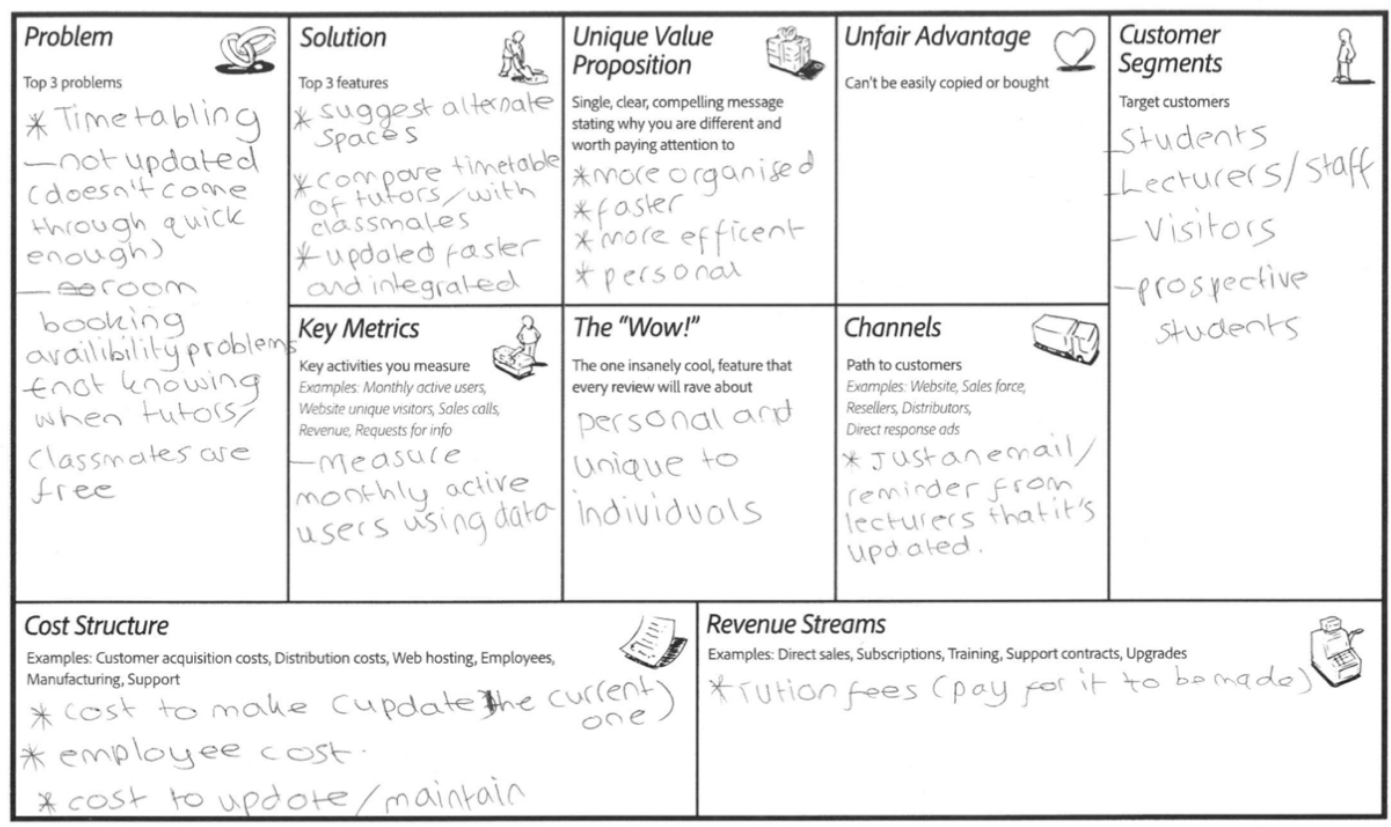

()(ㄱㅇㅇ(1)

Figure 3: The final selected idea using the Business Model Canvas [19].

The unique or 'wow' factor, as shown in Figure 3, for their new idea, was the ability to see when their friends, peers and tutors are free and to be able to book time with staff or peers directly, and to have all the University booking systems pull into their calendar or timetable so that their calendar is unique to them. 


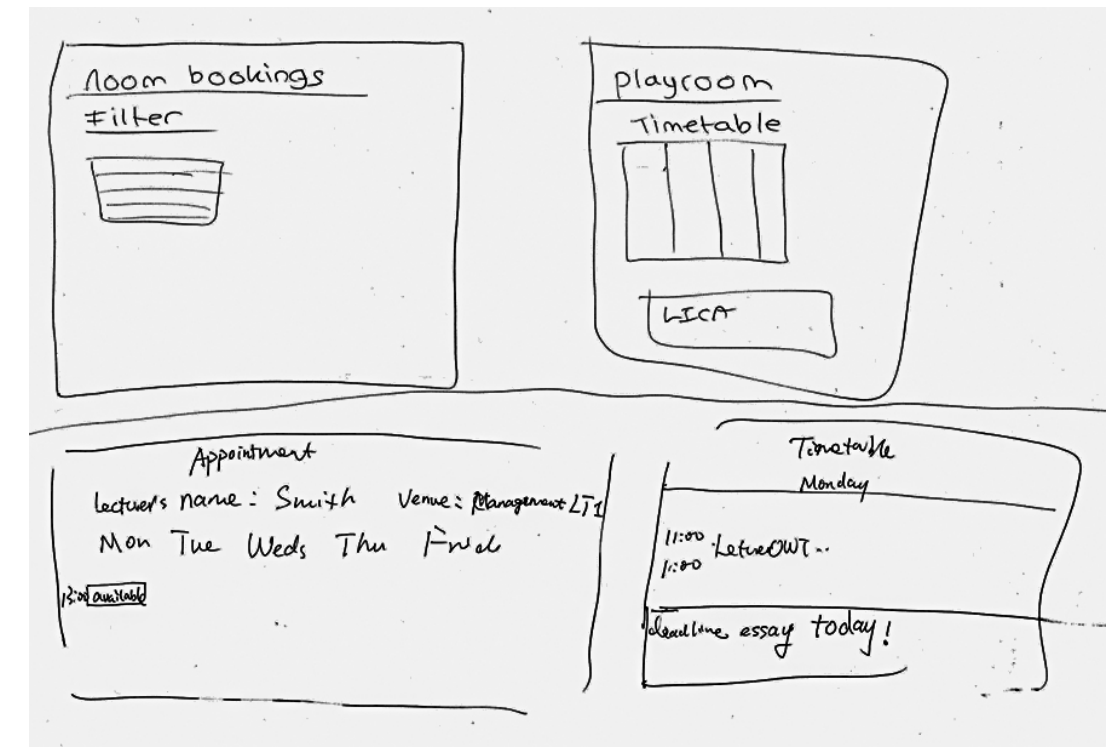

Figure 4: A subset of the final designs for the 'Academic Outcomes' workshop.

The above designs show a centralised place for booking rooms and study spaces (the University currently has two systems for this, only one of which displays in the student timetable), as well as a way of booking appointments with their tutors. The participants all agreed (as can be seen in the lower right corner of the above design) that all events no matter how they are booked should display in their student timetable. Further research into the idea they selected and their designs could be carried out on this. However, the context of this study focuses on the process in which these designs were created, and the effect gender played on this.

\subsection{Analysis}

The group discussions within the workshops were transcribed; when the participants were presenting one another's problems to the group in pairs, and secondly when solutions to the problems were self-presented and the top three selected. Whilst the final designs were collected, for the case of this paper they will not be used.

Thematic conversation analysis (TCA) was used by the transcripts being reviewed and the main themes selected through the observation of repeated patterns and knowledge of previous studies in this field. This was carried out by the transcripts being read through once with no agenda, simply to understand and refresh what had taken place. Following this, the transcripts were read to find where decisions were made, and these were then looked at in both what was being done and how (i.e. the thematic and conversation analysis). Once these had been outlined, it was clear that decisions were being made mostly by the male participants despite only two of the seven being male, so the transcripts were analysed again, with this time the focus being on the process decisions being made by the group's participants. Finally, the language itself being used by the participants was analysed using standard CA techniques such as recognising interruptions or who indicated who should be the next speaker.

Themes in each of these stages were raised by reflecting on previous literature [2], [14] and studies that had been read, to find support, contradictions or any poignant occurrences which may fall outside the existing literature. These results were then categorised into three areas, as detailed below.

\section{Results}


In examining the data, the main themes found included; raising problems in a group (one of the first stages of the innovation workshop), the language and conversational styles used and finally the practicality of group working. In this analysis, we will pay attention to how these were shaped by gender. These themes were found when thematically analysing the conversations when participants shared and grouped their problems and solutions. The group was asked to pair up, with one group of three, and present one another's problems to the group. When the same was done for solutions, they were asked to present their own.

\subsection{Problem Raising}

\subsubsection{Types of Problems Raised and Straight to Solutions}

The male participants mainly raised issues to do with the University's academic practices and facilities, for example the keyboards not being suitable, whereas the female participants raised more problems around the lifestyle of studying and how this fits into their lives, which can be seen below as M9 presents F7's problem. This link between decision making, or what constitutes a problem, and gender is supported by Park [20], who carried out a study which "statistically supported the argument that there exists a close relationship between gender role, decision style and leadership style."

\section{Excerpt 1: M9 presenting of F7's ideas.}

M9: Oh and finding time to balance social life with school life, I don't know... time management... and all that kinds of stuff. Especially when you have times where like assignments assigned weeks before it's due and you have this thing going on in your mind and it's like basically if it's very, if it's like $50 \%$ of your grade, just be worrying about it for the whole... All this time, you cannot go to social stuff without worrying about it.

When asked for problems, the men presented solutions to their problems straight away, for example the suggestion of "better keyboards" as opposed to the problem being raised that the current keyboards are not fit for purpose.

\section{Excerpt 2: F7 presenting of M2's ideas.}

F7: Um, so, better keyboards would be really handy. Um, the resources in the library, so for textbooks you either have to use an e-book or buy one for yourself so it'd be more handy to have more copies available in the library.

By presenting solutions before problems as requested this early in the process, then other ideas may not be brought forward by other individuals, in this case the women, as it was one of the male participants who voiced the solution first. Within PD, it is important to first fully understand the problems that are trying to be solved before solutions are presented to ensure that any solutions are appropriate. Part of this process is understanding the links between problems and creative solutions as part of PD; therefore this study involves unpacking how gender effects each part of this process.

\subsubsection{Organisation of Problems}

When presenting problems to the group, students were asked to work in smaller self-selected groups to explain one another's ideas to each other and then to present their partner's problems to the group. They split themselves into two mixed groups, and one group of three females, as Figure 1 shows. 
The group containing all women had already grouped their problems, and therefore didn't present one another's ideas but just the ones nearest to them.

Excerpt 3: The all-female group when presenting problems, had mixed up their ideas.

F1: $\quad$ We kinda mixed up everyone's so...

Facilitator: That's ok, you can all just present random ones.

F1: This one's yours I think... And it says the check in system's not stable, like sometimes you could be in like... in like... that room and it'll say you're not there.

This could be interpreted in two ways; firstly, that they did not clearly listen to the instructions, or secondly they were more collaborative. A larger sample size would be needed to draw any conclusions on this.

\subsection{Language and Conversation}

The language used by the participants throughout this process of PD, with regards to apologising and asking for help, seemed to hold strong differences when it came to gender. These differences are explored in detail below.

\subsubsection{Hedging: Apologetic language and taking up space}

After the group of three women had presented their problems, there was a pause and F12 embarrassingly said "we have a lot of problem[s]".

\section{Excerpt 4: The all-female group when presenting problems, had mixed all their sticky notes together.}

F12: $\quad$ We have a lot of problem.

Facilitator: There's three of you, there's gonna be... Excellent! Over to you guys then... If you guys are done?

F1/10/12: Yeah, I think so.

The way in which problems were presented in this group supports what Tannen [21] observed in small mixed gender groups, where there were "far more women than men", "when it came to present small-group findings to the class, each group that included a man had chosen the man to stand up and be the spokesperson." As in both mixed pairings, it was the male participant who spoke first, as well as F12 apologising for taking so long by saying "we have a lot of problem". This reinforces the willingness of men to speak and 'take up space', whereas generally women prefer not to. Tannen [21] also suggests that it is a manager's role to notice behaviour which silences women, and not for women to change their communication style.

It also seems important, considering reflexivity, to acknowledge that the researcher, who is a woman and who played the part of facilitator in the workshop, refers multiple times to the group as "guys", when the groups are either mixed or all female (see Excerpts 4 and 10). This could suggest an unconscious gender bias in language; however, the focus of this study is the interactions between the participants, so this will not be explored further in this paper. 
Excerpt 5: F8 apologising for being negative about the lecturers.

F8: Ok, I can go? Um, I have solutions, ok, I have three digital one and one non-digital. The non-digital would be giving trainings for lectures, to lecturers. Because, er, to provide nicer material and for them to have better presentation skills. Because I feel like not all lecturers are, erm... What am I trying to say? I think some of them have side jobs, or even lecturing is their side jobs. So, I mean I'm not surprised that they're bad at lecturing, 'cause they just... but not, sorry...

When presenting a solution around teaching, F8 clearly feels guilty for being negative by saying "because they just... but not... sorry...". This reinforces the notion that women feel guilty for having an opposing view, supported by Ngozi Adichie [22] who states that "we teach girls to shrink themselves, to make themselves smaller", which can be seen in Excerpt 7.

Excerpt 6: M2 is presenting F8's problems, is unclear on what she meant and attempts to change the subject, so the facilitator asks for clarification.

M2: Um... Lecture recordings, um, she finds that helpful as well the lecture recordings. Lectures are meant to be fifty minutes in length, and many times she's found lecture recordings to be of a shorter length, for example forty minutes, so she, um, it disrupts her? Um, her ability to... um... yeah... Next one!

Facilitator: Sorry, just for that one, is that because lectures are shorter than they're meant to be, or because the lecture recording's been cut off?

F8: $\quad$ I think both.

Excerpts 4, 5 and 6 all show examples of hedging. Hedging is the term referring to the linguistic style of 'hegding' your bets with phrases such as "I think", "you know" and "sort of" [23]-[25]. This is also found to be true in this study for the female participants, for example in Excerpt 4 where the female participants say "I think so" when asked if they've completed their stack of post-its, when it's clear through observation that they have or in Excerpt 6, where F8 says "I think both". Whether these are personality traits or representative of gender differences would require further research; however, this small study contains many examples of this behaviour from women. This is supported by Murphy [23] who states that "the use of hedges among females before a key word" is used "to avoid the appearance of playing the expert".

Holmes [24] suggests that hedging has two purposes, either to express speaker confidence e.g. "you know" or "reflecting uncertainty" e.g. "I think". The subjective nature of hedging could therefore be seen as a linguistic tool used by participants, not just as a means of interpretation. However, it is difficult to tell where hedging is used deliberately, for example to seem more approachable, or when it used due to genuine uncertainty. For example, in Excerpt 4, when asked if they had completed going through their notes, the female group responded with "I think so", when it was clear that they had, as they'd moved all their sticky notes. Whereas in Excerpt 6, where F8 says "I think both", they may not remember which of the two options they had been given, or they may be using hedging as a tool so as not to cause any offense. This ties into what Holmes later implies in 1990 [25] in that context around hedging is very important to consider.

Are more subtle analysis is perhaps required when it comes to hedging, to uncover not only how frequently, but also how it used [26]. Dixon and Foster [27] for example, found that hedging was used the same amount of time by both genders, unlike Holmes [24], but what Dixon and Foster did find was that the way that hedging was used was different. For example Holmes [24] outlines two functions of hedging as "modal" and 
"affective". Further research supporting this has shown that simply carrying out a numerical analysis on frequency shows no significant results [26], which supports Holmes' work [24]. These differences in findings further support the need for a more subtle analysis to find how hedging is used differently, then it would be very thought-provoking to see how this then ties into group design and innovation.

\subsubsection{Asking for Help}

In the smaller grouping of M2 and F8, they had opposite ways of asking for, or not asking for, help in explaining one another's ideas. M2 read each of F8's problems from a sticky note and when they did not understand or trailed off, they simply declared "next one!" and moved on, as can be seen in Excerpt 6. They were then asked by the facilitator to explain further which $\mathrm{F} 8$ then did.

The aim of asking participants to present one another's problems to the rest of the group had the aim of encouraging the group to talk and work together. In further research the role that gender plays on this could perhaps be considered with regards to empathy which may will be distributed differently by gender.

Later, when F8 was presenting the problems of M2 (see Excerpt 7), they admitted when they were unsure, saying to M2, "I forgot, can you say more about that?"

Excerpt 7: F8 is presenting M2's problems, is unclear on what he meant and therefore asks him for clarification.

F8: $\quad$ Mmm... As in some TAs would just sit down, play with their phone, or they would, they have, um a lack of knowledge regarding the workshop materials, and then... Exam parameters... is unfair... So... I forgot, can you say more about that?

M2: $\quad$ Yes, so for example, um, um, for [department name], there was two problem actually. Number one, one of mine was put in such a way where you must complete this question before moving onto the next.

This presents a lot to uncover. The stereotype around men not admitting to weakness is supported in this behaviour. What is perhaps more interesting is the female participant voicing her concern when she is unsure. Female students are two and a half times less likely to ask questions in academic seminars than their male counterparts [28]. Whereas what was seen in this study contradicted this.

\subsection{Group Practices}

\subsubsection{Writing: "l'll just do it."}

M2 asks the group "who's the best writer here?" and F1 responds "I'll just do it", to which M2 laughs, see below in Excerpt 8. From this point on F1 is the scribe for the group. F1 does however use this where she can to influence what is written down. "We internalize ideas from our socialization," [22] - if all that is ever presented to us is women as scribes, then we may not realise that we're reinforcing it our actions.

\section{Excerpt 8: The decision of who writes the category headings when categorising the problems.}

F7: $\quad$ The library can probably be one by itself.

M2: $\quad$ Yes, definitely.

F7: Who wants to write that? 
M2: Who's the best writer here?

F1: $\quad$ I'll just do it.

In their role, as 'scribe', F1 however was able to write out category headings without the whole group's approval, and wrote these down and showed the to the other women sat nearby who confirmed their support of the work.

Quast [29], discusses that Richard Branson, founder of the Virgin Group strongly believes that it should be everyone who makes notes in a meeting, being quoted to say; "men shouldn't take over the note taking from women, everyone should be taking notes." Journalistic articles such as "Taking Notes Isn't 'Women's Work': What To Do When You're The Default Admin" [30] show that being asked to take notes or take the role of 'scribe' is a consistent problem women are faced with.

However, what is perhaps more unusual in this instance, is that F1 herself volunteered for this role. This could be argued as either they wanted this role, or they were reinforcing a gender bias of which they may have been unaware.

\subsubsection{Leading and Turn Taking}

When all ideas had been presented, the participants were asked to select their top three ideas to work on further. M2 took the lead saying, "Let's determine which is the biggest problem first? Then we will find a solution which is best fitted for that biggest problem." They were heavily supported by F7 who repeatedly said "ok" after each leading statement by M2. M2 then led the discussion and took people around the table counting votes; "ok, so two timetabling, two library...". After the top three solutions have been decided on, M2 then again takes the lead suggesting the groups split up again, which they do based on what idea they voted for. In 1974, Sacks, Schegloff and Jefferson [31] attempted "to characterize, in its simplest systematic form, the organization of turn-taking for conversation, and to extract some of the interest of that organisation". One of the attributes of CA they found was transitions between speakers having "no gap and no overlap" were common and more significantly to this research that "turn order is not fixed, but varies." What was found in this study supports more recent theories of gender and turn taking by Kitzinger [14] in that gender plays a role who speaks next. As although in this study they went around the table clockwise, this was led by one of the two male participants. This is interesting and almost random, due to the turn taking simply being clockwise, but by this being led by a male participant brings equality into question.

Zingalesd et al. [32], state that men often achieve leadership roles regardless of past, remembered and claimed performance. They found "that women are selected to represent the group 33.3\% less often than their abilities would suggest". This is reinforced in this study by M2 consistently taking the lead and organising the group, see Excerpt 9 below.

Excerpt 9: When choosing their top three ideas to take forward to the next stage, $M 2$ took charge of the group.

Facilitator: It's just what is the most important to you guys?

F8: Maybe timetable then?

F1: $\quad$ I agree, $\quad$ um, so...

M2: $\quad$ Timetable as well then? 
F1: $\quad$ Timetable, whether that's with classmates, with lecturers, I think...

M2: $\quad O k$.

F1: $\quad$ That would be useful...

M2: $\quad$ Ok, so two timetabling, two library...

M9: $\quad H o w$ about lecturing? Because we mentioned about lecturers recording or like or the lectures, so each area maybe that sort of thing...

M2:

I agree with you on that, so how about I'm for lecture materials and lecture as well?

This gender difference when it comes to leadership was also found in previous research when groups were separated by gender, each of the male groups established a self-elected leader, and only one of the two female groups chose a leader based on ability [33].

\section{Analysis}

Participatory Design (PD) aims to give all stakeholders a role in the designing of a product. When it comes to a student's academic studies, the focus of the group in this trial, this should involve students of all backgrounds and genders. To not include a variety of participants is to strive for failure. However, even when a variety of students are selected, there are seemingly a range of gender differences which present themselves. Whether these are down to a group setting, or PD in a group setting, remains to be uncovered. However, the above results do clearly show a pattern of differences when it comes to gender. The main themes of problem raising, language and group practices which emerged are indicative of some wider issues at large, but this paper aims to analyse these themes with regards to PD.

Stokoe [34] states that "interaction can be analysed in ways that reveal how gender categories are routinely occasioned to accomplish some action". For example, if gender is used as motivation, this could be constructive or unconstructive when it comes to gender roles. Regardless, it important to consider how gender roles or categories effect the actions of participants. This study showed, for example, that when F1 volunteered for the task of writing down category headings. Through thematic conversation analysis on a small scale, details were unpicked which may normally have been missed. Combining the methodologies of theme analysis with conversation analysis may be the most appropriate way of uncovering cases of gender affecting group work in design. It is vital to be able to recognise these differences, in order to be able to calculate if, when broken down, this leads to better practices of innovation.

The differences in the raising of problems, with the different types of problems being raised and how these are raised could be an example of gender differences at large. For example, the solution first approach that was demonstrated in this workshop by the male participants could overshadow any ideas generated by others, which will not lead to a more diverse range of ideas. This could be addressed by putting something into place to stop solutions being raised until later in the process, perhaps with separate groups for male and female participants, or perhaps simply clearer instructions.

The language and conversation differences between genders that were noted in this study align with previous research by Speer and Stokoe [35] around the different conversation styles between men and women. This is also in line with the apologetic nature of speech by women and their lack of willingness to take up space due to the patriarchy in which they were raised [21]. However, what was analysed around language was one of 
the female participant's unapologetic request for more information. It could be argued that often women are expected to remain silent and not ask for help when it is needed, and it was a perhaps surprising and optimistic act within this study.

As for group practices, including the woman who volunteered to write and man who led the discussion and selection of the final ideas, there were strong gender differences. Mainstream media has commented upon this [30] and this study (see Excerpt 8) clearly shows examples of the expectations upon women to scribe for a group. In design workshops, this may be a barrier to the women being active participants in a group settings, as they're unable to fully engage due to the task of writing down, meaning they would never be able to raise their own thoughts and opinions.

With regards to turn taking and leadership, this study showed a clear example of a male assuming a leadership role. This study simply showed another example of a male participant taking the lead in the group activity. When it comes to participatory design, this could be seen as a real obstacle, as all stakeholders are supposed to have equal input into the product. Having equal input from all participants can cause complications and this should be led by a facilitator and the facilitator should not be imposing their view on the group. Which is why any participant assuming a leadership role could be seen as potentially problematic as they are extremely unlikely to represent all potential users of the product or service. Therefore, a male participant assuming this role without prompting is indicative of wider issues at large when it comes to the role gender plays on design in practice.

The next question would be, what can be done to break down this patriarchal structure in an innovative group setting? When carrying out design within an institution, this involves involving all participants throughout the design process. In most cases, this should include involving a diverse group of users and team members in order to design a product or service that is suitable for all potential users, otherwise the design recommendations made through the process of PD will be limited in their imagination.

\section{Conclusion}

This study is suggestive that gender plays a strong role in group dynamics with regards to innovation, and that thematic conversation analysis is an appropriate way of analysing this type of phenomenon. Despite its small sample size, there are too many similarities between the themes found in this workshop and existing literature to discount any findings. Subtle traces of gender conformity have been selected and analysed in this case of this innovation workshop around academic life at University. This is supported by Franklin [36] who observes that the dynamics men and women have in a group setting do not allow for true equality.

The above findings, on the differences displayed with regards to problem raising, apologetic language, asking for help, hedging and group practices such as writing and turn taking are all indicative of gender differences in PD. This ties back into the discussion around hedging made above where it is important to recognize the position of the talk, and to understand the context [25]. To deconstruct the effect gender has on this process, each of these areas must be taken and investigated in further detail. Due to the small sample size it is important to test if these issues would still hold when applied to a large proportion of the population. This study does however stand as a strong foundation for this research and gives direction in where thought should be applied. For example, would apologetic language still be used in single sex groups? Would turn taking still happen by simply going around the table but without a leader, or would a female leader step forwards? And depending on the outcome of this, what can be done to allow equality or equity in a group setting?

There is, of course, the argument that differences allow strength, and by encouraging equity in a group setting, we do not wish to remove participant's individuality and personality to establish all participants as being 'the same', but simply to allow themselves to unapologetically participate and put their ideas forward, in order for the design process to be successful and the strongest product recommendations to be proposed. Supported 
by Dourish [37] the implications that flow from this admittedly small scale piece of research allow reflection on how to best implement the practice of PD by taking account of gender differences. Dourish [37] argues that research can hold implications for any part of the research however, not just design. The implications of this study gives us an understanding as to how the participants contribute towards PD and how this may be effected by gender. Secondly, it gives grounding for further research towards the design of PD groups and how they may be carried out considering what has been found here around participant interaction. Furthermore, it is vital that when carrying out inclusive design, that it is not just numbers that are looked at to ensure equal representation, although this is vital, but how when this is done these interactions take place. A much more subtle analysis is needed in order to uncover recommendations and interactions for facilitators to use and look out for, so that requirements phases of designs can be better informed, and stronger products designed. It is my belief that this study will pave the way for further research in what can be done to break down any barriers caused by perceived gender in running innovation workshops within the university sector and further afield.

\section{ACKNOWLEDGMENTS}

I thank Dr Lynne Blair and Dr Mark Rouncefield for their supervision, support and guidance on this paper.

\section{REFERENCES}

[1] J. A. Rode, “A theoretical agenda for feminist HCI," Interact. Comput., 2011, doi: 10.1016/j.intcom.2011.04.005.

[2] E. H. Stokoe and A. Weatherall, "Gender, language, conversation analysis and feminism," Discourse Soc., vol. 13, no. 6, pp. 707-713, 2002, doi: 10.1177/0957926502013006751.

[3] B. Hansen, N., Dindler, C., Halskov, K., Iversen, O., Bossen, C., Basballe, D. and Schouten, "How Participatory Design Works.," Proc. 31st Aust. Conf. Human-Computer-Interaction., vol. 45, no. 4, p. 675,2019 , doi: $10.2307 / 591889$.

[4] A. K. Gupta, P. E. Tesluk, and M. S. Taylor, "Innovation at and Across Multiple Levels of Analysis," Organ. Sci., vol. 18, no. 6, pp. 885-897, 2007, doi: 10.1287/orsc.1070.0337.

[5] M. H. Fagan, "The influence of creative style and climate on software development team creativity: An exporatory study," Journal of Computer Information Systems. 2004, doi: 10.1080/08874417.2004.11647584.

[6] M. Steen, "Virtues in Participatory Design: Cooperation, Curiosity, Creativity, Empowerment and Reflexivity," Sci. Eng. Ethics, 2013, doi: 10.1007/s11948-012-9380-9.

[7] E. Balka, "Participatory design in women's organizations: The social world of organizational structure and the gendered nature of expertise," Gender, Work Organ., 1997, doi: 10.1111/14680432.00027 .

[8] S. Hester and D. Francis, "Doing Data: The Local Organization of a Sociological Interview," $B r . J$. Sociol., 1994, doi: 10.2307/591889.

[9] E. H. Stokoe, “Analysing gender and language," J. Socioling., 2005, doi: 10.1111/j.13606441.2005.00285.x.

[10] J. Sidnell, "Conversation analysis," in Sociolinguistics and Language Education, 2010.

[11] C. Kitzinger, "Doing feminist conversation analysis," Fem. Psychol., 2000, doi: 10.1177/0959353500010002001.

[12] Z. O'Leary, The essential guide to doing your research project, 3rd ed. SAGE, 2017. 
[13] C. Davis, "Feminist Rhetorical Practices in Digital Spaces," Comput. Compos., pp. 132-141, 2019.

[14] C. Kitzinger, "Developing feminist conversation analysis: A response to Wowk," Human Studies. 2008, doi: 10.1007/s10746-008-9088-7.

[15] C. Spinuzzi, "The methodology of participatory design,” Tech. Commun., pp. 163-174, 2005.

[16] D. Silverstein, P. Samuel, and N. Decarlo, The Innovator's Toolkit, 2nd ed. Hoboken, N.J.: Wiley, 2013.

[17] E. H. Stokoe and J. Smithson, "Making gender relevant: Conversation analysis and gender categories in interaction," Discourse Soc., vol. 12, no. 2, pp. 217-244, 2001, doi: $10.1177 / 0957926501012002005$.

[18] G. Guest, K. MacQueen, and E. Namey, Applied Thematic Analysis. SAGE, 2012.

[19] S. AG, "Strategyzer | Corporate Innovation Strategy, Tools \& Training," Businessmodelgeneration.com, 2019. http://businessmodelgeneration.com/ (accessed Nov. 21, 2019).

[20] D. Park, "Gender role, decision style and leadership style," Women Manag. Rev., vol. 11, no. 8, pp. 13-17, 1996, doi: 10.1108/09649429610148737.

[21] D. Tannen, Talking from 9 to 5. New York: Avon Books, 1994.

[22] C. Adichie, We Should All Be Feminists. Fourth Estate LTD, 2020.

[23] B. Murphy, Corpus and sociolinguistics : investigating age and gender in female talk. Amsterdam ; Philadelphia: John Benjamins Pub. Co, 2010.

[24] J. Holmes, "Functions of You Know in Women's and Men's Speech Language in Society," Source Lang. Soc., 1986.

[25] J. Holmes, "Hedges and boosters in women's and men's speech," Lang. Commun., 1990, doi: 10.1016/0271-5309(90)90002-S.

[26] A. Ashcroft, “'Hedging' and Gender in Participatory Design,” no. 1986, pp. 176-180, 2020.

[27] J. Dixon and D. Foster, “No Title,” J. Psycholinguist. Res., vol. 26, no. 1, pp. 89-107, 1997.

[28] A. J. Carter, A. Croft, D. Lukas, and G. M. Sandstrom, "Women's visibility in academic seminars: Women ask fewer questions than men," PLoS One, 2018, doi: 10.1371/journal.pone.0202743.

[29] L. Quast, "Ending Gender Bias: Why Richard Branson Says Everyone Should Take Meeting Notes, Not Just Women.," Forbes, 2015. https://www.forbes.com/sites/lisaquast/2015/08/31/endinggender-bias-why-richard-branson-says-everyone-should-take-meeting-notes-not-just-women/ (accessed Apr. 09, 2020).

[30] “Taking Notes Isn't 'Women's Work': What To Do When You're The Default Admin.," Forbes, 2013. https://www.forbes.com/sites/dailymuse/2013/10/18/taking-notes-isnt-womens-work-whatto-do-when-youre-the-default-admin (accessed Apr. 09, 2020).

[31] H. Sacks, E. A. Schegloff, and G. Jefferson, "A Simplest Systematics for the Organization of TurnTaking for Conversation,” Language (Baltim)., vol. 24, no. 2, pp. 111-134, 1974, doi: $10.2307 / 412243$.

[32] E. Reuben, P. Rey-Biel, P. Sapienza, and L. Zingales, "The emergence of male leadership in competitive environments," J. Econ. Behav. Organ., 2012, doi: 10.1016/j.jebo.2011.06.016. 
[33] A. Ashcroft, “A nice brain teaser,” 2018, doi: 10.1145/3196839.3196848.

[34] E. Stokoe, "On ethnomethodology, feminism, and the analysis of categorial reference to gender in talk-in-interaction,” Sociol. Rev., 2006, doi: 10.1111/j.1467-954X.2006.00626.x.

[35] S. A. Speer and E. Stokoe, Conversation and gender. Cambridge: Cambridge University Press, 2011.

[36] D. Franklin, "A Practical Guide to Gender Diversity for Computer Science Faculty," Synth. Lect. Prof. Career Adv. Sci. Eng., 2013, doi: 10.2200/s00495ed1v01y201304pro002.

[37] P. Dourish, “Implications for design,” 2006, doi: 10.1145/1124772.1124855. 